\title{
Clinical Characteristics of Children with Rett Syndrome
}

\author{
Zee-A Han, M.D., Ha Ra Jeon, M.D., Seong Woo Kim, M.D., Jin Young Park, M.D., Hee Jung Chung, M.D. ${ }^{1}$ \\ Departments of Physical Medicine and Rehabilitation, ${ }^{1}$ Pediatrics, National Health Insurance \\ Corporation Ilsan Hostpital, Goyang 410-719, Korea
}

Objective To identify the clinical characteristics and investigate function related aspects of Korean children with Rett syndrome.

Method A total of 26 patients diagnosed as Rett syndrome were clinically observed until the age of five or over. We surveyed past history, developmental history, and presence of typical clinical features of Rett syndrome. Furthermore, we investigated differences in clinical characteristics according to functional status and changes in clinical features related to growth.

Results There were no problems related to gestational, perinatal or neonatal history. Only 12 patients had an ultimate head circumference of less than 3 percentile. Developmental regression was definite in all patients. At final assessment, only 14 patients were able to walk. Twenty patients had an epileptic history requiring medication. Sixteen patients with scoliosis showed progression during serial follow-up. The percentage of patients who were able to walk before 16 months was higher in the high function group than the low function group. The age of regression was 5.4 and 4.0 years in the high and low function group respectively, but the difference was not statistically significant. Scoliosis was more severe and seizure onset age was younger in the low function group. Conclusion We investigated 26 clinical characteristics in Korean children with Rett syndrome. Their clinical features change according to age, and we believe such knowledge could be utilized in rehabilitation to minimize their disabilities.

Key Words Rett syndrome, Clinical feature, Gait

Received August 31, 2011; Accepted April 2, 2012

Corresponding author: Ha Ra Jeon

Department of Physical Medicine and Rehabilitation, National Health Insurance Corporation Ilsan Hostpital, 100 Ilsan-ro, Ilsan-donggu, Goyang 410-719, Korea

Tel: +82-31-900-0361, Fax: +82-31-900-3343, E-mail: snoopyhara@ hanmail.net

(c) This is an open-access article distributed under the terms of the Creative Commons Attribution Non-Commercial License (http:// creativecommons.org/licenses/by-nc/3.0) which permits unrestricted noncommercial use, distribution, and reproduction in any medium, provided the original work is properly cited.

Copyright () 2012 by Korean Academy of Rehabilitation Medicine

\section{INTRODUCTION}

Rett syndrome is a progressive neurodevelopmental disorder in females and a common cause of mental retardation. ${ }^{1}$ The prevalence is one per 10,000 female children, and mutation of the MECP2 gene in the $\mathrm{X}$ chromosome is known to be involved. ${ }^{2}$ Children with Rett syndrome usually undergo normal development in the early stages of growth but subsequently regress in areas of motor and language. Appropriate hand usage becomes difficult due to stereotypic hand movements as retardation of head circumference growth ensues. Other clinical features 
such as loss of communication ability, ataxia, autistic tendencies and epilepsy have been reported to occur. ${ }^{1,3}$ Children with Rett syndrome typically progress through four stages; the early stagnation stage (6-18 months), the second regression stage (1-4 years), the third pseudostationary stage, and the fourth late motor deterioration stage. ${ }^{4}$ Based on these clinical features, international congresses have reported on revised clinical diagnostic criteria for Rett syndrome. ${ }^{5}$ However, there is ambiguity in interpreting the criteria. Stagnation of head circumference is not a feature that is observed in all Rett syndrome children and developmental delay can occur early after birth. In addition problems in gait development may be due to ataxia. ${ }^{6}$ These variations and ambiguities make diagnostic decisions difficult for clinicians when examining children with suspected Rett syndrome.

Most Korean studies on Rett syndrome have reported on the genetics of Rett syndrome or have been studies of electroencephalographic results. None have focused on the clinical features of Korean Rett syndrome patients. The aim of this study is to confirm the known clinical features of Rett syndrome patients who visited our rehabilitation clinic and further focus on functional outcomes as well as contribute to decision making in the clinical field.

\section{MATERIALS AND METHODS}

We recruited 26 patients with mutations of the MECP2 gene from 2001 to December of 2010, who visited the Rehabilitation Department of National Health Insurance Corporation Ilsan Hospital and who were diagnosed due to clinical features with classic Rett syndrome. ${ }^{7,8}$ All patients were followed up to a stage where they would be past the regression stage, which was at least 5 years and older. They were all female children, with ages averaging 60.4 months and ranging from 18 to 176 months at their first visit to our hospital.

The birth history and medical history were investigated with additional histories on development, regression and onset of regression. We surveyed periods where each developmental areas had peaked and also looked for presence of developmental regression, as well as regression periods through caregiver interview, questionnaires, and longitudinal review of medical records on growth parameters and physical examination. Based on normal developmental curves, we classified the patients by their weights and heights as groups of less than $3 \%$, $3-10 \%$, $10-25 \%$, $25-50 \%$, 50-75\%o, and $75-90 \%$. We defined patients as growth retarded if the patients were either consistently included in the less than $3 \%$ group or developmental delay group. Hand function regression was used to describe those patients who had lost their ability to reach or grasp. Regression of language was used to define loss of vocalization of formerly able words. Patients who had lost their ability to stand, walk, and change position independently were defined to have regression in gross motor activities. The patients were evaluated through careful history taking and follow up by a rehabilitation specialist in our hospital's outpatient clinic. We also investigated the prevalence of characteristic clinical features of Rett syndrome such as sterotype, growth retardation in head circumference, epilepsy, and scoliosis. Furthermore, we analysed associations between functional levels (independent walking, independent standing, independent sitting, unable to sit) and specific clinical features.

SPSS PC 16.0 was used for the statistical analysis, and descriptive statistics were applied for analysis of growth parameters, prevalences of specific clinical features and analysis of functional levels. Chi-square test was used to analyze correlations between final functional levels and degree of scoliosis and t-test was applied to find correlations between final functional level and onset of epilepsy. The significance level was set at $\mathrm{p}<0.05$.

\section{RESULTS}

There were no risk factors in birth history related to neuro-developmental disease such as preterm birth, low birth weight, perinatal asphyxia, and neonatal convulsion. However, there was one patient with a history of neonatal jaundice treated by phototherapy. There were no significant findings related to family or gravidity.

During follow up, 13 patients (50.0\%) showed growth retardation in height, and 15 patients $(57.7 \%)$ in weight. 12 patients (46.2\%) showed microcephaly of less than $3 \%$, but due to the lack of head circumference data at birth, changes in head circumference could not be analyzed. Among the 9 patients with initial normal head circumferences, 4 patients had circumference regression to less than $3 \%$.

When gathering developmental history, most caregivers 
Table 1. Age of Patients

\begin{tabular}{|lrr}
\hline & $\begin{array}{r}\text { High function } \\
\text { group }(\mathbf{n}=14)\end{array}$ & $\begin{array}{r}\text { Low function } \\
\text { group }(\mathbf{n}=\mathbf{1 2})\end{array}$ \\
\hline Age on first visit & $4.7(1.5-12.1)$ & $4.7(1.7-14.7)$ \\
\hline Age on final visit & $13.2(2.0-21.0)$ & $10.8(3.0-22.0)$ \\
\hline
\end{tabular}

Table 2. Motor Developmental History

\begin{tabular}{|cc}
\hline \multicolumn{1}{c}{ Motor function } & n \\
\hline Developmental history until 6 months & \\
\hline Delayed & 5 \\
\hline Normal & 21 \\
\hline Independent walking at any age & 7 \\
\hline No & 19 \\
\hline Yes & \\
\hline Independent walking before 16 months & 14 \\
\hline No & 5 \\
\hline Yes
\end{tabular}

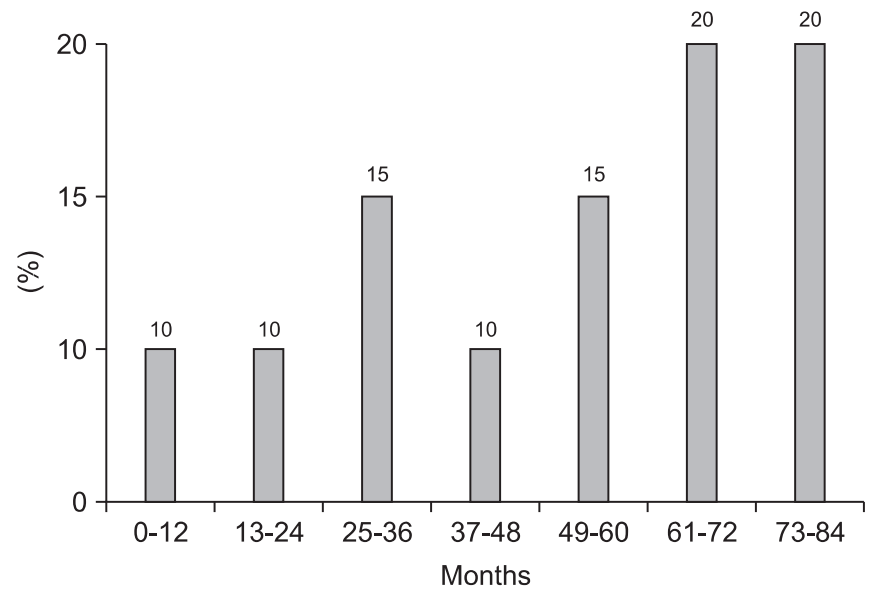

Fig. 1. Onset age of seizure event: there are no affected age groups.

were unable to remember periods of eye contact, cooing etc. However, most were able to consistently remember milestones related to gross motor development. Gross motor development during the initial 6 months after birth were normal in 21 patients $(80.7 \%)$ and delayed in 5 patients (19.2\%). Independent walking had been possible in 19 patients $(73.1 \%)$ where as 7 patients $(26.9 \%)$ had never experienced independent walking. Only 5 patients (26.3\%) could walk normally before 16 months, and the other 14 patients $(73.7 \%)$ could walk after 16 months (Table 2).

Developmental regression was seen in all the patients,
Table 3. Characteristics of High Function Group and Low Function Group

\begin{tabular}{lcc}
\hline & $\begin{array}{c}\text { High func- } \\
\text { tion group } \\
(\mathbf{n}=\mathbf{1 4})\end{array}$ & $\begin{array}{c}\text { Low func- } \\
\text { tion group } \\
(\mathbf{n}=\mathbf{1 2})\end{array}$ \\
\hline Prior independent walking (n)* & 14 & 6 \\
Walking before 16 month (n)* & 4 & 1 \\
Microcephaly (n) & 7 & 5 \\
Seizure history (n) & 11 & 9 \\
Regression age (year) & 5.42 & 4.01 \\
Seizure onset age (month)* & 64.36 & 30.56 \\
\hline
\end{tabular}

${ }^{*} \mathrm{p}<0.05$

and the average onset age of the regression was 49 months. Among regressive features, regression in hand function was most common and was seen in 21 patients (80.8\%). Regression in language development was seen in 16 patients $(61.5 \%)$ and gross motor development in 8 patients $(30.8 \%)$.

$20(76.9 \%)$ patients manifested with epilepsy that required antiepileptic medication. The onset age of epilepsy was 61-72 months in 4 patients, within 12 months in 2 patients, and 73-84 months and more in 4 patients (Fig. 1).

16 patients $(61.5 \%)$ had scoliosis with a Cobb's angle of 10 degrees or more at the age of 5 , and the angle got larger progressively by serial follow up.

Final functional status of the patients was as follows. Indoor independent gait was possible in 14 but was not in 9 patients. Among the 9 patients who were unable to independently walk, independent standing was possible in 4 patients and independent sitting in 5 patients. 3 patients were unable to sit independently. Final functional status was used to divide the patients into high and low function groups depending upon independent walking status. Developmental histories and clinical features between each group were compared.

In the high function group, microcephaly with head circumferences of less than $3 \%$ o was observed in 7 (50.5\%) out of the 14 patients. Five $(41.7 \%)$ out of the 12 patients had microcephaly in the low function group. There was no statistical difference between the two groups (Table $3)$. The high function group included 4 patients (28.6\%) capable of independent walking before 16 months and 10 patients $(71.4 \%)$ capable of independent walking after 16 months. In the low function group, there were 1 (8.3\%) and $5(41.7 \%)$ patients who could walk independently be- 
Table 4. Presence of Scoliosis in High and Low Function Group

\begin{tabular}{lcc}
\hline & $\begin{array}{c}\text { High function } \\
\text { group (n=12) }\end{array}$ & $\begin{array}{c}\text { Low function } \\
\text { group (n=8) }\end{array}$ \\
\hline Scoliosis* $^{*}$ & $8(66.67 \%)$ & $8(100 \%)$ \\
\hline Average Cobb's angle* & 13.6 & 26.8 \\
\hline
\end{tabular}

${ }^{*} \mathrm{p}<0.05$

fore and after 16 months respectively. Six (50.5\%) patients had never experienced walking in the low function group. When comparing independent walking status before and after 16 months, there was statistical difference between the low and high function groups $(\mathrm{p}<0.01)$ (Table 3$)$. In addition, there was statistical difference in the developmental status of independent walking between the high and low function groups $(\mathrm{p}<0.01)$ (Table 3$)$.

The onset of the regression in hand function, language, or gross motor activities was 5.4 years in the high function group and 4.0 years in the low function group, showing a later onset trend in the high function group. However, these differences had no statistical significance (Table 3).

We also analyzed the development of scoliosis according to functional levels and prevalence. Cobb's angle was higher in the low function group but there was no significant difference between the two groups $(\mathrm{p}<0.05)$ (Table 4$)$.

There were 11 patients $(78.6 \%)$ and 9 patients $(75.0 \%)$ with histories of epilepsy in the high and low function group respectively but prevalences did not show statistical difference. The onset of epilepsy was 64.4 months in the high function group and 30.6 months in the low function group, showing statistically significant differences between the two groups $(\mathrm{p}<0.05)$ (Table 3$)$.

\section{DISCUSSION}

Rett syndrome was first reported by Andrea Rett in 1960s and gained interest after Hagberg et al. ${ }^{9}$ reported on characteristic clinical features of Rett syndrome in 1983. The mutation of the MECP2 gene located on Xq28 was revealed to be the cause of Rett syndrome in 1999, but mutation of the MECP2 gene is only an assistive clue in the diagnosis of Rett syndrome since diagnosis is based on clinical criteria. ${ }^{2,3}$ According to the modified diagnostic criteria presented by Hagberg in 2002, these are the necessary conditions for diagnosing classic Rett syndrome; 1) normal prenatal and perinatal history, 2) normal development during the first 6 months, 3) normal head circumference at birth, 4) growth retardation in head circumference after birth, 5) loss of voluntary hand function during age 6 months through 2 years, 6 ) stereotypical movement of hands, 7) problems in communication or social interaction, regression of language, and cognitive problem, and 8) regression or impairment in movement. Elsewhere, there are 8 assistive and $5 \mathrm{ex}-$ clusive conditions. In this study, we recruited cases that corresponded with classic Rett syndrome and cases with mutation of the MECP2 gene. Clinical features were examined since the criteria described above have areas of ambiguity in clinical application. There were some cases where growth retardation in head circumference, which is known to be a necessary condition for the diagnosis, was not definite. In addition there were cases where abnormal development occurred in the early days after birth, and cases where independent walking was impossible due to apraxia, etc.

In this study, about half of the patients showed microcephaly, and among the patients with known head circumferences at birth, half were proven to have subsequent microcephaly. These results correspond to previous studies indicating that although growth retardation of head circumference is a necessary condition for the diagnosis of Rett syndrome, it is not observed in all patients. ${ }^{10}$ The revised diagnostic criteria for Rett syndrome by the Rett Search Consortium in 2010 excluded growth retardation of head circumference after birth as an essential criterion for the diagnosis of Rett syndrome. ${ }^{11}$

Patients with classic Rett syndrome have no specific problems in the course of birth and are known to undergo normal development for 6 months after birth. However, some recent studies report on tendencies of decreased interaction with the environment, autistic features, and decreased muscle tone. Moreover, one study revealed that the patients' general movements were abnormal during the first 6 months via video analysis. ${ }^{12}$ Our study was highly dependent on caregiver reports on the early developmental periods of the patients. Although efforts were made to retrieve information on various developmental milestones, there were limitations and only major gross motor developmental status was analyzed. As a result, according to caregiver descriptions, most of the patients underwent normal development in early periods after birth, and only $19 \%$ were reported to have delayed 
development. Other studies showed similar results with normal psychiatric development seen in $70 \%$ and a 2 to 4 month delay in gross motor development seen in $30 \%{ }^{13}$ Although it is difficult to conclude definitely on early period gross motor delay in children with Rett syndrome, many studies are reporting abnormal development in the early periods of Rett syndrome.

In this study, $26.9 \%$ of patients had never walked independently. This result corresponds to results by Smeets et al. ${ }^{14}$ reporting that $29 \%$ of Rett syndrome patients had been unable to walk independently.

In this study, the average age of regression onset was 49 months with regressions most frequently occurring in areas of hand function. Downs also reported that $40 \%$ of Rett syndrome patients showed loss of hand function at the age of 3 to $4 .{ }^{15}$ According to a long term study in Sweden, regression begins at 19 months on average, and at the age of 2.5 years, apraxia or involuntary stereotype is observed in all patients. ${ }^{16}$ This study shows an earlier age of regression onset compared to our study. According to Segawa, seterotypical hand movements in Rett syndrome patients may be due to a dysfunction in the supplementary motor area which provides antagonistic signals to the hand opposite of that performing voluntary movement. Such dysfunctions of the supplementary motor area and premotor cortex can occur due to problems in the dopamine pathway of the basal ganglia or substantia nigra. ${ }^{17}$ Among the subjects included in this study, regression symptoms were recognized earlier in those diagnosed with Rett syndrome at our hospital's rehabilitation clinic, whereas regression periods in those diagnosed at other departments and institutions were detected at a later stage. This study has limitations in that it relied primarily on caregiver descriptions in the absence of video interpretations or other objective data. This may be due to a lack of education about Rett syndrome among the general population, delaying the detection and downgrading the seriousness of atypical behaviors of children.

Epilepsy is known to develop in $60-80 \%$ patients of Rett syndrome, and this study showed similar percentages. ${ }^{4,18}$ However, the onset age of epilepsy was somewhat different. It is known that the prevalence of epilepsy increases after the third regression period and in a study by Glaze et al., ${ }^{18}$ epilepsy rarely develops before the age of 2 years. However in our study, epilepsy occurred evenly in all ages. Although epilepsy is known to be related to the patients' functional level, we found no differences in the prevalence of epilepsy between the high and low function group. Rather, only onset age of epilepsy differed in these two groups, with epilepsy occuring later in high function group than in the low function group. Although there are studies reporting on the absence of an association between onset age of epilepsy and clinical severity, a number of studies are showing an increased incidence of epilepsy in Rett syndrome as age increases.

The most common musculoskeletal complication in Rett syndrome is scoliosis, and the prevalence varies according to reports but ranges from $48-87 \% .{ }^{19}$ The prevalence of scoliosis increases as developmental disability severity increases. It also increases when regression occurs before 6 months, when there has been no prior experience of walking, or when regression of gait has begun before musculoskeletal maturation. ${ }^{20}$ These findings, according to Ager and Alan, are due to mutations of R294X and R306C in the MECP2 gene in chromosome $\mathrm{Xq28}$, which are related to mild developmental problems and to a decreased risk of scoliosis development. ${ }^{21,22}$ In this study, about $60 \%$ of patients had scoliosis, and it was more frequent in the high function than in the low function group as in other studies. Riise et al. ${ }^{23}$ also reported that in Rett syndrome patients where scoliosis was not a problem, all were capable of independent walking. Thus rehabilitative strategies are needed to prevent and treat scoliosis in Rett syndrome patients who are unable to walk.

\section{CONCLUSION}

Through this study, we were able to identify characteristic features of Rett syndrome as well as confirm that ambiguous descriptions included in the widely known diagnostic criteria of Rett syndrome are not always observed in all patients. Taken together, the 2010 revised diagnostic criteria of Rett syndrome is more appropriate when diagnosing Rett syndrome.

Furthermore, decrements in functional decline after the age of 5 were more profound in the low function group in whom independent gait was not possible. In addition, the onset of epilepsy was earlier, and scoliosis more severe.

This study can be applied in the rehabilitation field to minimize disability in patients with Rett syndrome. 


\section{REFERENCES}

1. Matijevic T, Knezevic J, Slavica M, Pavelic J. Rett syndrome: from the gene to the disease. Eur Neurol 2009; 61: 3-10

2. Amir RE, Van den Veyer IB, Wan M, Tran CQ, Francke $\mathrm{U}$, Zoghbi HY. Rett syndrome is caused by mutation in $\mathrm{X}$-linked MECP2, encoding methyl-CpG-binding protein 2. Nat Genet 1999; 23: 185-188

3. Williamson SL, Christodoulou J. Rett syndrome: new clinical and molecular insights. Eur J Hum Genet 2006; 14: 896-903

4. Nissenkorn A, Gak E, Vecsler M, Reznik H, Menascu S, Ben Zeev B. Epilepsy in Rett syndrome-the experience of a National Rett Center. Epilepsia 2010; 51: 12521258

5. Hagberg B, Hanefeld F, Percy A, Skjeldal O. An update on clinically applicable diagnostic criteria in Rett syndrome. Eur J Paediatr Neurol 2002; 6: 293-297

6. Percy AK, Neul JL, Glaze DG, Notil KJ, Skinner SA, Khwaja O, Lee HS, Lane JB, Barrish JO, Annese F, et al. Rett syndrome diagnostic criteria: lessons from the natural history study. Ann Neurol 2010; 68: 951-955

7. The Rett syndrome diagnostic criteria work group. Diagnostic criteria for Rett syndrome. Ann Neurol 1988; 23: $425-428$

8. Hagberg BA, Skjeldal OH. Rett variants: a suggested model for inclusion criteria. Pediatr Neurol 1994; 11: 5-11

9. Hagberg B, Aicardi J, Dias K, Ramos O. A progressive syndrome of autism, dementia, ataxia and loss of purposeful hand use in girls: Rett's syndrome: report of 35 cases. Ann Neurol 1983; 14: 471-479

10. Hagberg G, Stenborn Y, Witt Engerström I. Head growth in Rett syndrome. Acta Paediatr 2000; 89: 198202

11. Neul JL, Kaufmann WE, Glaze DG, Christodoulou J, Clarke AJ, Bahi-Buisson N, Leonard H, Bailey MES, Schanen NC, Zappella M, et al. Rett syndrome: revised diagnostic criteria and nomenclature. Ann Neu- rol 2010; 68: 944-950

12. Einspieler C, Kerr AM, Prechtl HF. Is the early development of girls with Rett disorder really normal? Pediatr Res 2005; 57: 696-700

13. Bashina VM, Simashkova NV, Grachev VV, Gorbachevskaya NL. Speech and motor disturbances in Rett syndrome. Neurosci Behav Physiol 2002; 32: 323-327

14. Smeets E, Schollen E, Moog U, Mattijs G, Herbergs J, Smeets H, Curfs L, Schrander-Stumpel C, Fryns JP. Rett syndrome in adolescent and adult females: clinical and molecular genetic findings. Am J Med Genet A 2003; 122A: 227-233

15. Downs J, Bebbington A, Kaufmann WE, Leonard H. Longitudinal hand function in Rett syndrome. J Child Neurol 2011; 26: 334-340

16. Witt Engerström I. Age-related occurrence of signs and symptoms in the Rett syndrome. Brain Dev 1992; 14: S11-20

17. Segawa M. Pathophysiology of Rett syndrome from the stand point of clinical characteristics. Brain Dev 2001; 23 Suppl 1: S94-98

18. Glaze DG, Percy AK, Skinner S, Motil KJ, Neul JL, Barrish JO, Lane JB, Geerts SP, Annese F, Graham J, et al. Epilepsy and the natural history of Rett syndrome. Neurology 2010; 74: 909-912

19. Lidstrom J, Stokland E, Hagberg B. Scoliosis in Rett syndrome. Clinical and biological aspects. Spine 1994; 19: 1632-1635

20. Kopp SE. Scoliosis and Rett syndrome. Dev Med Child Neurol 2011; 53: 582-583

21. Ager S, Fyfe S, Christodoulou J, Jacoby P, Schmitt L, Leonard H. Predictors of scoliosis in Rett syndrome. J Child Neurol 2006; 21: 809-813

22. Percy AK, Lee HS, Neul JL, Lane JB, Skinner SA, Geerts SP, Annese F, Graham J, Mcnair L, Motil KJ, et al. Profiling scoliosis in Rett syndrome. Pediatr Res 2010; 67: 435-439

23. Riise R, Brox JI, Sorensen R, Skjeldal OH. Spinal deformity and disability in patients with Rett syndrome. Dev Med Child Neurol 2011; 53: 653-657 